\title{
Wealth inequality and optimal monetary policy
}

\author{
Ryoji Hiraguchi ${ }^{* \dagger}$
}

July 23,2008

\begin{abstract}
We study the money-in-the-utility-function model in which agents are heterogeneous in their initial wealth. We show that the Friedman rule is not optimal even if the government uses non-linear income taxation for redistribution. A positive nominal interest rate raises social welfare since it relaxes the incentive compatibility constraint of highly endowed agents. Although the model is close to da Costa and Werning ("On the optimality of the Friedman rule with heterogeneous agents and nonlinear income taxation", Journal of Political Economy, 2008(116), 82-112) who investigate skill heterogeneity, the role of the nominal interest rate here differs from the one in their model.
\end{abstract}

Keywords: monetary policy; private information; Friedman rule

*Institute of Economic Research, Kyoto University

†Address: Yoshida-honmachi, Sakyo-ku, Kyoto, Japan. Phone: 075-753-7133. Fax: 075-753-7193. Email: hiraguchi@kier.kyoto-u.ac.jp 


\section{Introduction}

A major goal of monetary policy analysis is to obtain the optimal policy rule. A number of authors investigate the optimality of the Friedman rule of setting the nominal interest rate to zero in representative agent models. Chari and Kehoe (1999), for example, show that the Friedman rule is optimal in most of the basic monetary models without frictions. On the other hand, Schmitt-Grohe and Uribe (2004) investigate a model with imperfect competition and show that a positive nominal interest rate works as a tax on rent and it raises welfare. Heer (2003) and Arseneau and Chugh (2007) consider models with search frictions and they also show that the Friedman rule is not optimal.

Recently da Costa and Werning (2008) (henceforth DW) have developed a heterogeneous agent monetary model in which each agent has different skill level and it is private information. They show that when the government can use incentive-compatible nonlinear income taxation for redistribution, the Friedman rule is optimal. A redistribution through the expansionary monetary policy does not improve social welfare in their model. While they made significant contributions to the analysis of monetary models with heterogeneous agents, we do not know much about how monetary policy should respond to different kinds of heterogeneity, just as Kocherlakota (2005) pointed out.

This paper investigates the money-in-the-utility-function model in which each agent is heterogeneous in her initial wealth and the level is private information. As in DW, the government uses incentive-compatible non-linear income taxation for redistribution. The set-up is almost the same as DW and the only difference is that we investigate wealth heterogeneity while DW study skill heterogeneity. ${ }^{1}$ 
Our model has two types of agents, highly endowed agents and poorly endowed agents. They are identical ex-ante, but they receive idiosyncratic shocks on their wealth at the beginning of period 0 . The government maximizes the expected utility of the originally identical agents by choosing nonlinear income taxation (fiscal policy) and the nominal interest rate (monetary policy).

In our model, the first best allocation follows the Friedman rule, but it is not incentivecompatible. At the first best setting, agents work the same amount of time and their wealth is perfectly redistributed, since the government wants to equalize their marginal utilities of consumption and also their marginal disutilities of labor. Thus poorly endowed agents receive higher labor income than wealthy agents, even though their labor supply is the same. The wealthy agents therefore have an incentive to understate their type.

The paper shows that even if the government can use the incentive-compatible income tax for redistribution, deviations from the Friedman rule raise social welfare. This result is contrary to DW's finding. A positive nominal interest rate is welfare-improving because it relaxes the incentive constraints of highly endowed agents. Although it generates a consumption-labor distortion, this negative effect is negligible if the interest rate is around zero.

To understand how the nominal interest rate affects the incentive constraint, let us compare a poorly endowed agent with a highly endowed (rich) agent who claims to be poor. Although they receive the same labor income, the rich agent wants to hold money more than the poor agent. Since the nominal interest rate makes money more costly, it lowers the utility gain from deviating the truthtelling strategy and it relaxes the incentive 
constraint of the rich agent. Here the nominal interest rate plays a role of a penalty for misreporting.

In DW, the same mechanism does not work. In their model with skill heterogeneity, the incentive constraints of high-skilled agents are binding. However, if a high-skilled agent understates her type, her money holding is the same as that of the low-skilled agent whom she mimics. Therefore the positive nominal interest rate cannot relax the incentive constraint of the high skilled agent.

There is a growing list of papers which investigates the optimality of the Friedman rule in heterogeneous agent models. Bhattacharya et al. (2004,2005) and Ireland (2005) analyze models in which agents are different in their monetary satiation levels or in their endowment levels. They find that a positive nominal interest rate has a distributional effect and it can be welfare improving. Palivos (2005) studies an OLG model in which agents are heterogeneous in the degree of altruism towards their children. He also shows that inflation has a distributional effect and it raises social welfare.

The limitation of these papers is that in their models, the government can only use lump-sum tax. If the redistributive fiscal policy is available, monetary redistribution may be unnecessary or even be harmful. In this paper, we show that even if the government can use a strong fiscal instrument for redistribution, the nominal interest rate is effective if agents are heterogeneous in their wealth. Ireland (2005) raises a question about which policies, monetary or fiscal, work effectively in redistributing income between groups. In our model, monetary and fiscal policies are not substitutes and a mix of the two policies raises social welfare. 
In addition to DW, Antinolfi et al. (2007) have recently investigated the role of the nominal interest rate on the incentive constraint. In Antinolfi et al. (2007), there are cash agents who store value in currency, and credit agents who use currency and loans. The planner tries to maximize the expected utility of the agents by choosing the nominal interest rate subject to an incentive constraint of credit agents. They show that the optimum rate of inflation is positive. Although their conclusion on the effectiveness of the positive nominal interest rate is the same as this paper, heterogeneity in their model is different from the one in our model. Also, Antinolfi et al. (2007) analyze an endowment economy in which the nonlinear labor income tax is unavailable. Therefore the role of the nominal interest rate in our model differs from the one in their model.

As Chari and Kehoe (1999) pointed out, the Friedman rule is related to the uniform commodity tax theorem. Cremer et al. (2001) show that in a model where agents differ both in ability and endowment, commodity taxation or subsidy may improve the welfare. However, their formula on the optimal commodity tax rates is complex and it is not clear exactly when the optimal commodity tax rate is nonzero. Hence, we cannot directly apply their results to our monetary model.

The rest of the paper is organized as follows. Section 2 describes the model. Section 3 characterizes the first best allocation. Section 4 investigates the incentive-compatible government policies. Section 5 concludes the paper. Proofs are in the Appendix. 


\section{The model}

In this section, we set-up the model. The model closely follows DW, Ljungqvist and Sargent (2001) and Alvarez et al. (2004).

\subsection{Preferences}

Time is discrete and denoted by $t=0,1,2, \ldots \infty$. There is a continuum of agents with measure one. They are ex-ante identical and their instantaneous utility function is

$$
U(c, m, l)=u(c, m)-g(l)
$$

where $c$ is consumption, $m$ is money in real term, $l$ is work time, $u$ is the utility of consumption and money balance, $g$ is the disutility of labor. The preferences of the ex-ante homogeneous agent over consumption $c_{t}$, real money balance $m_{t}$ and labor $l_{t}$ are

$$
(1-\beta) \sum_{t=0}^{\infty} \beta^{t} U\left(c_{t}, m_{t}, l_{t}\right),
$$

where $\beta<1$ is a discount factor.

The utility function $u$ is concave, twice continuously differentiable and strictly increasing in $c$. For each value of $c$, each agent is satiated with money holding when $m=\phi(c)$, where $\phi$ satisfies $\phi(0)=0$ and $\phi^{\prime}(c)>0$. The marginal utility of money $u_{m}=\partial u / \partial m$ satisfies $u_{m}(c, m)>0$ if $m<\phi(c), u_{m}(c, m)=0$ if $m=\phi(c)$ and $u_{m}(c, m)<0$ if $m>\phi(c)$. Therefore no agent wants to hold money more than the threshold level $\phi(c)$. If $r=0$, then $m=\phi(c)$ at the optimal. We assume that the consumption good and money are normal goods and that $u(c, \phi(c))$ is strictly concave in $c$. 
The disutility of labor $g$ is twice continuously differentiable, strictly increasing $\left(g^{\prime}(y)>\right.$ $0)$, strictly convex $\left(g^{\prime \prime}(y)>0\right)$ and it satisfies $g(0)=0$. Production is characterized by a linear technology and one unit of labor produces one unit of single good. Here we assume that each agent has identical skill. This assumption is different from DW.

\subsection{Wealth shock}

In this subsection, we introduce wealth heterogeneity in our model. The ex-ante identical agent receives a mean zero idiosyncratic shock on the initial endowment of real bonds. Similar shocks has been studied by Cremer et al. (2001) and De Nardi et al. (1999), although their models are non-monetary.

The level of the wealth shock is private information of each agent and is described by a parameter $\theta$, which is equal to the initial value of real bonds. The parameter $\theta$ can take only two values, $\theta_{H}>0$ and $\theta_{L}<0$, and it is independently distributed across agents. Let $\Theta=\left\{\theta_{H}, \theta_{L}\right\}$ denote the set of $\theta$. Also let $\operatorname{Pr}\left(\theta=\theta_{H}\right)=\pi_{H}>0$ and $\operatorname{Pr}\left(\theta=\theta_{L}\right)=\pi_{L}>0$ denote the probability distribution of $\theta$. Since the wealth shock $\theta$ is mean zero,

$$
\mathbf{E}[\theta]=\pi_{H} \theta_{H}+\pi_{L} \theta_{L}=0 .
$$

In what follows, we call an agent who receives the shock $\theta$ as an agent $\theta$. By the law of large numbers, the probability $\pi_{i}(i=H, L)$ is equal to the ex-post density of agent $\theta_{i}$ (see Albanesi and Sleet (2006)). 


\subsection{Intertemporal optimization problem}

This subsection describes the intertemporal optimization problem of agents. After receiving the wealth shock, each agent reports her shock parameter to the government according to the reporting strategy $\sigma(\theta): \Theta \rightarrow \Theta$. We determine $\sigma$ later.

If an agent $\theta$ reports $\hat{\theta}$ as her type, the government assigns an allocation $\left\{x_{t}(\hat{\theta}), y_{t}(\hat{\theta})\right\}_{t=0}^{\infty}$ to her, where $x_{t}$ is labor income and $y_{t}$ is labor supply in period $t$. Labor tax in period $t$ is therefore equal to $T_{t}(\hat{\theta})=y_{t}(\hat{\theta})-x_{t}(\hat{\theta})$. The government also determines the nominal interest rate in each period as the monetary policy.

Now we consider the intertemporal optimization problem of the agent $\theta$ with the reporting strategy $\hat{\theta}$. Let $V(\hat{\theta}, \theta)$ denote her value function. The agent $\theta$ solves

$$
\begin{aligned}
V(\hat{\theta}, \theta) \equiv \max _{\left\{c_{t}, M_{t+1}, B_{t+1}, l_{t}\right\}_{t=0}^{\infty}}\left[(1-\beta) \sum_{t=0}^{\infty} \beta^{t} U\left(c_{t}, m_{t}, l_{t}\right)\right], \\
\text { s.t. } c_{t}+\frac{M_{t+1}}{p_{t}}+\frac{B_{t+1}}{R_{t}}=B_{t}+\frac{M_{t}}{p_{t}}+x_{t}(\hat{\theta}), \\
l_{t}=y_{t}(\hat{\theta}), \\
\left(M_{0}(\theta), B_{0}(\theta)\right)=(0, \theta) \text { given, }
\end{aligned}
$$

where $M_{t+1}$ is nominal balance held between times $t$ and $t+1, p_{t}$ is the price level, $m_{t}=M_{t+1} / p_{t}$ is the real balance, $B_{t}$ is the real value of government bond holdings that mature at the beginning of time $t$, and $R_{t}$ is the real rate of return on the bonds. Equation (4) is the budget constraint and Equation (5) is the labor assignment by the government. The nominal interest rate is given by $i_{t}=R_{t} /\left(p_{t} / p_{t+1}\right)-1$, where $p_{t} / p_{t+1}$ is the rate of return on money. From the arbitrage condition $R_{t} \geq p_{t} / p_{t+1}, i_{t} \geq 0$. The initial wealth of agent $\theta$ is heterogeneous in real bonds $B_{0}(\theta)$, but not in money $M_{0}(\theta)$. 
We impose the transversality conditions on money and bonds for every agent:

$$
\lim _{t \rightarrow \infty}\left(\prod_{i=0}^{t} R_{i}^{-1}\right) B_{t+1}(\theta)=\lim _{t \rightarrow \infty}\left(\prod_{i=0}^{t} R_{i}^{-1}\right) \frac{M_{t+1}(\theta)}{p_{t}}=0
$$

Using (7), we can consolidate the sequence of budget constraints:

$$
\sum_{t=0}^{\infty} q_{t}\left[c_{t}+r_{t} m_{t}-x_{t}(\hat{\theta})\right]=\theta
$$

where $r_{t}=i_{t} /\left(1+i_{t}\right), q_{0}=1$ and $q_{t}=\prod_{i=0}^{t-1} R_{i}^{-1}$ if $t>0$. In the present value budget constraint (8), $q_{t}$ is the price of good in period $t$ and $r_{t}$ is the opportunity cost of holding money. The reporting strategy $\sigma(\theta)$ is determined by

$$
\sigma(\theta) \in \underset{\hat{\theta} \in \Theta}{\operatorname{argmax}} V(\hat{\theta}, \theta)
$$

In what follows, we call $r_{t}=i_{t} /\left(1+i_{t}\right)$ as the nominal interest rate, instead of $i_{t}$ itself. Obviously there exists a one-to-one correspondence between $r_{t}$ and $i_{t}$. Formally, the government policy is defined as follows.

Definition 1 A government policy $\left\{\mathbf{X}_{t}, \mathbf{Y}_{t}, r_{t}\right\}_{t=0}^{\infty}$ in which $\mathbf{X}_{t}=\left(x_{t}\left(\theta_{H}\right), x_{t}\left(\theta_{L}\right)\right)$ and $\mathbf{Y}_{t}=\left(y_{t}\left(\theta_{H}\right), y_{t}\left(\theta_{L}\right)\right)$ is an allocation of labor, income, and the nominal interest rate. Here $x_{t}\left(\theta_{i}\right)$ and $y_{t}\left(\theta_{i}\right)$ are labor income and labor supply of an agent who reports $\theta_{i}$ as her type, respectively. The third term $r_{t}$ is the nominal interest rate.

We also define the stationary policy.

Definition 2 A stationary government policy is a time-independent government policy $\{\mathbf{X}, \mathbf{Y}, r\}_{t=0}^{\infty}$ in which $\mathbf{X}=\left(x\left(\theta_{H}\right), x\left(\theta_{L}\right)\right)$ and $\mathbf{Y}=\left(y\left(\theta_{H}\right), y\left(\theta_{L}\right)\right)$ 


\subsection{Stationary equilibrium}

In this subsection, we follow DW and characterize the stationary equilibrium with price $q_{t}=\beta^{t}(t \geq 0)$ and with the stationary government policy $\{\mathbf{X}, \mathbf{Y}, r\}_{t=0}^{\infty} .{ }^{2}$ Since the budget constraint is written as $\sum_{t=0}^{\infty} \beta^{t}\left\{c_{t}+r m_{t}-(x(\hat{\theta})+\alpha \theta)\right\} \leq 0$ where $\alpha=1-\beta$, the optimal $c_{t}$ and $m_{t}$ satisfy

$$
\left(c_{t}, m_{t}\right)=\underset{(c, m): c+r m=x(\hat{\theta})+\alpha \theta}{\operatorname{argmax}} u(c, m) .
$$

Let $v(x, r)=\max _{(c, m): c+r m=x} u(c, m)$ denote the indirect utility function. Using $v$, we can simply express the value function $V(\hat{\theta}, \theta)$ in $(3)$ as follows:

$$
V(\hat{\theta}, \theta)=(1-\beta) \sum_{t=0}^{\infty} \beta^{t}[v(x(\hat{\theta})+\alpha \theta, r)-g(y(\hat{\theta}))]=v(x(\hat{\theta})+\alpha \theta, r)-g(y(\hat{\theta})) .
$$

The government policy $\{\mathbf{X}, \mathbf{Y}, r\}_{t=0}^{\infty}$ is incentive-compatible if and only if

$$
V(\theta, \theta)=\max _{\hat{\theta} \in \Theta} V(\hat{\theta}, \theta) \quad \text { for all } \theta \in \Theta
$$

If the policy satisfies (10), each agent adopts the truth-telling strategy $\sigma(\theta)=\theta$. It follows from (9) that the incentive constraint (10) holds if and only if

$$
v(x(\theta)+\alpha \theta, r)-g(y(\theta)) \geq v(x(\hat{\theta})+\alpha \theta, r)-g(y(\hat{\theta})) \quad \text { for all } \theta, \hat{\theta} \in \Theta
$$

From the revelation principle, we can concentrate our attentions on incentive-compatible government policies. If a stationary policy $\{\mathbf{X}, \mathbf{Y}, r\}_{t=0}^{\infty}$ is incentive-compatible, the value function of an agent $\theta$ is equal to

$$
V(\theta, \theta)=v(x(\theta)+\alpha \theta, r)-g(y(\theta))
$$




\subsection{Optimal government policy}

In this subsection, we formalize the optimal government policy. In what follows, we call an agent with wealth shock $\theta_{H}\left(\theta_{L}\right)$ as individual $\mathrm{H}$ (individual $\mathrm{L}$ ). The government maximizes the expected utility of the ex-ante identical agent,

$$
\mathbf{E}_{\theta}[V(\theta, \theta)]=\sum_{i=H, L} \pi_{i}\left[v\left(x\left(\theta_{i}\right)+\alpha \theta_{i}, r\right)-g\left(y\left(\theta_{i}\right)\right)\right] .
$$

The government maximizes $\mathbf{E}_{\theta}[V(\theta, \theta)]$ by choosing the nominal interest rate and the incentive-compatible income taxation. The government expenditure is a constant $G>0$.

The budget constraint of the government in period $t$ is given by

$$
\sum_{i=H, L} \pi_{i}\left[\frac{M_{t+1}\left(\theta_{i}\right)-M_{t}\left(\theta_{i}\right)}{p_{t}}+\frac{B_{t+1}\left(\theta_{i}\right)}{R_{t}}-B_{t}\left(\theta_{i}\right)+y\left(\theta_{i}\right)-x\left(\theta_{i}\right)\right] \geq G .
$$

Let $[c(x, r), m(x, r)]=\operatorname{argmax}_{c+r m=x} u(c, m)$ denote the consumption/money demand functions. If the policy is incentive-compatible, consumption of individual $i$ in period $t$ is $c_{t}\left(\theta_{i}\right)=c\left(x\left(\theta_{i}\right)+\alpha \theta_{i}, r\right)$. Hence the budget constraint of individual $i$ is

$$
c\left(x\left(\theta_{i}\right)+\alpha \theta_{i}, r\right)+\frac{M_{t+1}\left(\theta_{i}\right)}{p_{t}}+\frac{B_{t+1}\left(\theta_{i}\right)}{R_{t}}=B_{t}\left(\theta_{i}\right)+\frac{M_{t}\left(\theta_{i}\right)}{p_{t}}+x_{t}\left(\theta_{i}\right) .
$$

Substituting (13) into (12) yields the following resource constraint:

$$
\sum_{i=H, L} \pi_{i}\left[y\left(\theta_{i}\right)-c\left(x\left(\theta_{i}\right)+\alpha \theta_{i}, r\right)\right] \geq G .
$$

At the equilibrium, the budget constraint of the government (12) coincides with the feasibility constraint. Formally, we define the optimal policy as follows.

Definition 3 The optimal (stationary) government policy $\{\mathbf{X}, \mathbf{Y}, r\}_{t=0}^{\infty}$ is a policy which maximizes the expected utility of agents $\mathbf{E}_{\theta}[V(\theta, \theta)]$ subject to the incentive compatibility constraint (11) and the feasibility constraint (14). 


\section{First-best allocation}

In this section, we characterize the first best allocation without the incentive constraints and shows that the allocation satisfies the Friedman rule but it violates the incentive compatibility of the highly endowed agents. For simplicity, we let $x_{i}=x\left(\theta_{i}\right), y_{i}=y\left(\theta_{i}\right)$, and $\bar{\theta}_{i}=\alpha \theta_{i}(i=H, L)$.

\subsection{Optimality of the Friedman rule}

In this section, we set-up the optimization problem of the government. Here the government maximizes social welfare only subject to the budget constraint. Let $c^{c}(v, r)$ and $m^{c}(v, r)$ denote the compensated demand function for consumption and money when the required utility is $v$ and the nominal interest rate is $r$. These functions are defined as

$$
\left[c^{c}(v, r), m^{c}(v, r)\right]=\underset{(c, m)}{\operatorname{argmin}}(c+r m) \text { s.t. } u(c, m) \geq v
$$

Following Mirrlees (1976) and Ebert (1992), here we express the problem of the government by using the compensated demand functions:

$$
\max _{v_{H}, v_{L}, y_{L}, y_{H}, r} \sum_{i=H, L}\left[v_{i}-g\left(y_{i}\right)\right] \pi_{i} \quad \text { s.t. } \sum_{i=H, L}\left\{y_{i}-c^{c}\left(v_{i}, r\right)\right\} \pi_{i} \geq G
$$

where $v_{i}$ is the utility of individual $i$ from consumption and money and $y_{i}$ is her labor supply. In the problem (15), the nominal interest rate $r$ does not affect the utility $v_{i}-g\left(y_{i}\right)$ and it only tightens the resource constraint. Note that $c_{r}^{c}\left(v_{i}, r\right)=\partial c^{c}\left(v_{i}, r\right) / \partial r>0$, because if money is costly, consumption has to be raised to achieve the same utility $v_{i}$. Therefore the optimal nominal interest rate is equal to zero. 


\subsection{Violations of incentive constraints}

In this subsection, we explain the reason why the first best allocation is not incentivecompatible. First we characterize the allocation. If $r=0$, then the Lagrangian is

$$
L=\sum_{i=H, L}\left[v_{i}-g\left(y_{i}\right)\right] \pi_{i}+\lambda\left[\sum_{i=H, L}\left\{y_{i}-c^{c}\left(v_{i}, 0\right)\right\} \pi_{i}-G\right],
$$

where $\lambda$ is the Lagrange multiplier on the resource constraint. The first order conditions on $v_{i}$ and $y_{i}$ are given by

$$
\begin{aligned}
& v_{i}: \lambda=1 / c_{v}^{c}\left(v_{H}, 0\right)=1 / c_{v}^{c}\left(v_{L}, 0\right), \\
& y_{i}: \lambda=g^{\prime}\left(y_{H}\right)=g^{\prime}\left(y_{L}\right),
\end{aligned}
$$

where $c_{v}^{c}(v, r)=\partial c^{c}(v, r) / \partial v$. Note that $1 / c_{v}^{c}(v, 0)=u_{c}\left(c^{c}(v, 0), m^{c}(v, 0)\right)$ is the marginal utility of consumption. ${ }^{3}$ The first order conditions imply that the marginal utilities of consumption and the marginal disutilities of labor are equalized across agents at the first best setting. Hence all agents consume and work in the same manner regardless of the wealth heterogeneity.

At the first best allocation, labor income of individual $\mathrm{H}$ is lower than that of individual L, although they work the same amount of time. This is because the government wants to redistribute their endowments perfectly through the income taxation. Therefore, in this case, individual $\mathrm{H}$ has an incentive to understate her type. The first best allocation does not satisfy the incentive constraint. 


\section{Incentive compatible policy}

In this section, we obtain the optimal and incentive-compatible fiscal and monetary policies and show that the nominal interest rate is strictly positive at the optimal.

\subsection{Set-up}

This subsection defines the problem of the government. Let us denote the expenditure function by $e(v, r)=c^{c}(v, r)+r m^{c}(v, r) .{ }^{4}$ The problem is written as follows:

$$
\begin{aligned}
\left(\mathbf{P}_{\mathbf{I C}}\right): \max & \sum_{i=H, L}\left[v_{i}-g\left(y_{i}\right)\right] \pi_{i}, \\
\text { s.t. } \sum_{i=H, L}\left\{y_{i}-c^{c}\left(v_{i}, r\right)\right\} \pi_{i} & \geq G, \\
v_{H}-g\left(y_{H}\right) & \geq v\left(\left[e\left(v_{L}, r\right)-\bar{\theta}_{L}\right]+\bar{\theta}_{H}, r\right)-g\left(y_{L}\right), \\
v_{L}-g\left(y_{L}\right) & \geq v\left(\left[e\left(v_{H}, r\right)-\bar{\theta}_{H}\right]+\bar{\theta}_{L}, r\right)-g\left(y_{H}\right), \\
r & \geq 0,
\end{aligned}
$$

where (16) is the resource constraint, (17) is the incentive constraint of individual $\mathrm{H}$, (18) is the incentive constraint of individual L and (19) is the non-negativity constraint on the nominal interest rate. Since individual $i$ spends $\bar{\theta}_{i}$ from her wealth each period, her utility is equal to $v_{i}$ if her labor income $x_{i}$ is $x_{i}=e\left(v_{i}, r\right)-\bar{\theta}_{i}$.

The constraint (17) is explained as follows. If individual $\mathrm{H}$ truthfully reports her type, her total expenditure (labor income plus wealth) is $x_{H}+\bar{\theta}_{H}=e\left(v_{H}, r\right)$ and her utility is equal to the left hand side of (17). On the other hand, if the agent claims to be individual $\mathrm{L}$, then her expenditure is equal to $x_{L}+\bar{\theta}_{H}=e\left(v_{L}, r\right)-\bar{\theta}_{L}+\bar{\theta}_{H}$. Hence her utility is equal to the right hand side of (17). 


\subsection{Relaxed problem}

This subsection shows that the incentive constraint of individual L is not binding. Let us consider the following problem $\left(\mathbf{P}_{\mathbf{I C}}^{\prime}\right)$ without the incentive constraints of individual L:

$$
\left(\mathbf{P}_{\mathbf{I C}}^{\prime}\right): \max \sum_{i=H, L}\left[v_{i}-g\left(y_{i}\right)\right] \pi_{i} \quad \text { s.t. }(16),(17) \text { and (19). }
$$

The Lagrangian of the relaxed problem $\left(\mathbf{P}_{\mathbf{I C}}^{\prime}\right)$ is

$$
\begin{aligned}
L= & \sum_{i=H, L}\left[v_{i}-g\left(y_{i}\right)\right] \pi_{i}+\lambda\left[\sum_{i=H, L} \pi_{i}\left\{y_{i}-c^{c}\left(v_{i}, r\right)\right\}-G\right] \\
& +\mu\left[v_{H}-g\left(y_{H}\right)-v\left(e\left(v_{L}, r\right)-\bar{\theta}_{L}+\bar{\theta}_{H}, r\right)+g\left(y_{L}\right)\right]+\tau r,
\end{aligned}
$$

where $\lambda, \mu$, and $\tau$ are the multipliers on the resource constraint, incentive constraint and the non-negativity constraint of the nominal interest rate, respectively. The first order conditions with respect to $y_{H}$ and $y_{L}$ are written as

$$
\begin{gathered}
y_{H}: \lambda \pi_{H}-\left(\mu+\pi_{H}\right) g^{\prime}\left(y_{H}\right)=0 . \\
y_{L}: \lambda \pi_{L}-\left(\mu-\pi_{L}\right) g^{\prime}\left(y_{L}\right)=0 .
\end{gathered}
$$

Equation (20) implies that labor of individual $\mathrm{H}$ has two negative effects, one $\left(-\pi_{H} g^{\prime}\left(y_{H}\right)\right)$ on her utility and the other one $\left(-\mu g^{\prime}\left(y_{H}\right)\right)$ on the incentive constraint $(17) .{ }^{5}$ The sum of these effects is equal to the shadow value of consumption $\lambda \pi_{H}$. Equation (21) can be explained similarly, but labor of individual L has a positive effect on (17). Equations (20) and (21) together imply

$$
y_{H}<y_{L}
$$

Individual L works harder than individual $\mathrm{H}$ although they have the same skill, since labor supply of individual $\mathrm{H}$ is more costly if the government cares the incentive constraint. 
Next we compare the labor income of individual $\mathrm{H}, x_{H}=e\left(v_{H}, r\right)-\bar{\theta}_{H}$ with that of individual L, $x_{L}=e\left(v_{L}, r\right)-\bar{\theta}_{L}$. Since the constraint (17) is binding, we have

$$
v\left(x_{H}+\bar{\theta}_{H}, r\right)-v\left(x_{L}+\bar{\theta}_{H}, r\right)=g\left(y_{H}\right)-g\left(y_{L}\right) .
$$

Since $y_{H}<y_{L}$, we get $x_{H}<x_{L}$. Individual $H$ receives lower labor income than individual L. These results lead to the following proposition.

Proposition 1 A solution to $\left(\mathbf{P}_{\mathbf{I C}}^{\prime}\right)$ satisfies the incentive constraint of individual L, (18). Therefore the two problems $\left(\mathbf{P}_{\mathbf{I C}}\right)$ and $\left(\mathbf{P}_{\mathbf{I C}}^{\prime}\right)$ coincide.

Proof. See appendix.

In what follows, we investigate the relaxed problem $\left(\mathbf{P}_{\mathbf{I C}}^{\prime}\right)$.

\subsection{Non-optimality of the Friedman rule}

In this subsection, we show that the Friedman rule is not optimal. Here we use the following lemma which is derived from the envelope theorem.

Lemma 1 The following holds.

$$
\begin{aligned}
& v_{r}(x, r)=-m u_{c}(x-r m, m)=-m v_{x}(x-r m, m), \\
& e_{r}(v, r)=m^{c}(v, r)=m(e(v, r), r), \\
& c_{r}^{c}(v, r)=-r m_{r}^{c}(v, r) .
\end{aligned}
$$

Proof. See Appendix. 
The first order condition on the nominal interest rate, $\partial L / \partial r$ can be written as

$$
\frac{\partial L}{\partial r}=-\lambda \sum_{i=H, L}\left[c_{r}^{c}\left(v_{i}, r\right) \pi_{i}\right]+\mu \frac{d}{d r} v\left(e\left(v_{L}, r\right)+\omega, r\right)+\tau,
$$

where $\omega=\bar{\theta}_{H}-\bar{\theta}_{L}>0$ is the difference in wealth. The first and second terms denote the effect of $r$ on the resource constraint (16) and on the incentive constraint (17), respectively. The third term $\tau \geq 0$ is the multiplier on the nonnegativity constraint on $r$.

The first term $\sum_{i}\left[c_{r}^{c}\left(v_{i}, r\right) \pi_{i}\right]$ is equal to zero if $r=0$ from equation (26). The effect of the nominal interest rate on the resource constraint is non-positive, but it is equal to zero around the Friedman rule.

Next we consider the second term $\mu d v\left(e\left(v_{L}, r\right)+\omega, r\right) / d r$. If this is positive, the nominal interest rate relaxes the incentive constraint. Using (24) in Lemma 1, we get

$$
\begin{aligned}
\frac{d v\left(e\left(v_{L}, r\right)+\omega, r\right)}{d r} & =e_{r}\left(v_{L}, r\right) v_{x}\left(e\left(v_{L}, r\right)+\omega, r\right)+v_{r}\left(e\left(v_{L}, r\right)+\omega, r\right) \\
& =\left\{m\left(e\left(v_{L}, r\right)+\omega, r\right)-m\left(e\left(v_{L}, r\right), r\right)\right\} v_{x}\left(e\left(v_{L}, r\right)+\omega, r\right) .
\end{aligned}
$$

Since money is a normal good by assumption, $m\left(e\left(v_{L}, r\right)+\omega, r\right)>m\left(e\left(v_{L}, r\right), r\right)$. This implies that the money demand of individual $\mathrm{H}$ who understates her type is greater than that of individual $\mathrm{L}$ whom she mimics. Here the incentive constraint is not slack and then $\mu>0$. Therefore $\mu d v\left(e\left(v_{L}, r\right)+\omega, r\right) / d r>0$. These results lead to the following proposition.

Proposition 2 The Friedman rule is not optimal.

Proof. In equation (27), the first term is zero and the second term is strictly positive. Hence $\partial L / \partial r>0$ if $r=0$. 


\subsection{Role of positive nominal interest rate}

In this subsection, we explain why a positive nominal interest rate raises social welfare.

On the contrary, suppose that an optimal government policy $Z$ follows the Friedman rule.

We derive a contradiction by following four steps below.

1) Find a policy $Z^{1}$ such that $r>0$ and the utility of agents is unchanged from $Z$.

2) Show that $Z^{1}$ satisfies the resource constraint and the incentive constraint.

3) Define a policy $Z^{2}$ by changing the labor allocations of $Z^{1}$ to increase welfare.

4) Show that $Z^{2}$ satisfies feasibility and incentive compatibility.

Let $v_{i}(i=H, L)$ denote individual $i$ 's utility from consumption and money under $Z$. Also let $y_{i}$ denote the labor of individual $i$. The total utility is equal to $v_{i}-g\left(y_{i}\right)$.

Now consider a new policy $Z^{1}$ such that individual $i$ gets the same utility $\left(v_{i}\right)$ from consumption and money and work the same amount of time $\left(y_{i}\right)$ but the nominal interest rate $\Delta r>0$ is positive.

First, the new government policy $Z^{1}$ satisfies the resource constraint if $\Delta r$ is small, since the increase of the compensated demand by the new policy, $c_{r}^{c}\left(v_{i}, 0\right) \Delta r$ is zero (see (26)). The effect of labor-consumption distortion on the feasibility constraint is negligible if the nominal interest rate is small.

Next, $Z^{1}$ is incentive-compatible. To see this, consider an agent of individual $\mathrm{H}$ who claims to be individual L. Let us call her individual $\mathrm{L}^{*}$. The new policy $Z^{1}$ has two opposing effects on her utility. First, money holding is now costly and her consumption is reduced by $m\left(e\left(v_{L}, 0\right)+\omega, 0\right) \Delta r$. Second, the government raises her income by $m\left(e\left(v_{L}, 0\right), 0\right) \Delta r$ to compensate for the consumption loss of individual L and to keep 
their utility $v_{L}$.

The problem for individual $\mathrm{L}^{*}$ is that she holds money more than individual $\mathrm{L}$ whom she mimics and the income compensation is not sufficient to cover the consumption reduction. ${ }^{6}$ Thus $Z^{1}$ reduces the utility of individual $\mathrm{L}^{*}$ and it relaxes the incentive constraint. Note that $Z^{1}$ satisfies the incentive constraint of individual $\mathrm{L}$ if $\Delta r$ is small, since it is not binding under $Z$.

Here individual $\mathrm{H}$ works less harder than individual $\mathrm{L}\left(y_{H}<y_{L}\right)$ since labor of individual $\mathrm{H}$ tightens the incentive constraint and then it is more costly. Now suppose that the government reduces individual L's labor by $d y / \pi_{L}>0$ and raises individual H's labor by $d y / \pi_{H}>0$, where $d y>0$ is constant. For sufficiently small $d y$, this policy change satisfies the feasibility and the incentive compatibility. Such a redistribution of labor supply from individual $\mathrm{L}$ to individual $\mathrm{H}$ is welfare-improving, since it contributes to equalize the disutilities of labor across agents. In other words, it lowers the expected disutility of labor, $\pi_{L} g\left(y_{L}\right)+\pi_{H} g\left(y_{H}\right)$. This contradicts the assumption that $Z$ is the optimal government policy.

In DW, the same mechanism does not work. In their model, the incentive compatibility constraints of high skilled agents are binding. However, if a high skilled agent underreports her type, her money holding is exactly the same as that of the low skilled agent whom she claims to be. The nominal interest rate cannot relax the incentive constraint and then it cannot increase social welfare (see DW for detail). 


\section{Conclusion}

In this paper we investigate the money-in-utility-function model where agents are heterogeneous in their initial wealth. We show that a deviation from the Friedman rule increases social welfare since a positive nominal interest rate relaxes the incentive constraints. Kocherlakota (2005) raises a question about how monetary policy should respond to various kinds of agent specific shocks. Although the wealth shock considered here is simple, this paper provides some insight into his question. This paper could lead to a better understanding of monetary policy analysis in a heterogeneous agent model.

\section{Acknowledgements:}

I thank Narayana Kocherlakota for valuable comments.

\section{Notes}

\footnotetext{
${ }^{1}$ Some authors recently investigate the roles of economic policies in infinite horizon models with wealth heterogeneity. For example, Garcia-Penalosa and Turnovsky (in press) and Jin (in press) investigate endogenous growth models with wealth inequality and analyze the effect of fiscal and monetary policies on growth. However, they do not analyze the social welfare which is the main focus of this paper.
}

${ }^{2}$ An agent $\theta$ who reports $\hat{\theta}$ as her type maximizes her utility (2) subject to the budget constraint $\sum_{t=0}^{\infty} \beta^{t}\left\{c_{t}+r m_{t}-x(\hat{\theta})\right\} \leq \theta$. Hence the equilibrium consumption and money are also stationary.

${ }^{3}$ Differentiating the equality $u\left(c^{c}(v, 0), m^{c}(v, 0)\right)=v$ in $v$ yields $c_{v}^{c}(v, 0) u_{c}=1$.

${ }^{4}$ The function is defined as $e(v, r)=\min _{(c, m)}(c+r m)$ s.t. $u(c, m) \geq v$.

${ }^{5}$ Since the first best allocation is not incentive compatible, $\mu>0$.

${ }^{6}$ This implies that $m\left(e\left(v_{L}, 0\right)+\omega, 0\right)>m\left(e\left(v_{L}, r\right), 0\right)$. 


\section{Appendix}

\section{A Proof of Proposition 1}

Since $v$ is strictly concave, for $k$ and $K$ such that $K>k \geq 0$, we have

$$
\frac{\partial}{\partial \theta}[v(K+\theta, r)-v(k+\theta, r)]<0
$$

Since $x_{L} \geq x_{H}$, Equation (28) implies

$$
v\left(x_{L}+\bar{\theta}_{L}, r\right)-v\left(x_{H}+\bar{\theta}_{L}, r\right) \geq v\left(x_{L}+\bar{\theta}_{H}, r\right)-v\left(x_{H}+\bar{\theta}_{L}, r\right) .
$$

Substituting (23) into (29) yields

$$
v\left(x_{L}+\bar{\theta}_{L}, r\right)-v\left(x_{H}+\bar{\theta}_{L}, r\right) \geq g\left(y_{L}\right)-g\left(y_{H}\right) .
$$

This is the same as (18). Therefore the constraint (18) is automatically satisfied if (29) is binding.

\section{B Proof of Lemma 1}

First, since $v(x, r)=\max _{m} u(x-r m, m)$, the envelope theorem implies equation (24). Next, we apply the envelope theorem to the expenditure function $e(u, r)=\min _{(c, m)}(c+r m)$ to get (25). Finally, differentiating $c^{c}(v, r)+r m^{c}(v, r)=e(v, r)$ with respect to $r$ yields $(26)$. 


\section{References}

[1] Albanesi, Stefania and Christopher Sleet (2006) Dynamic optimal taxation with private information. Review of Economic Studies 73, 1-30.

[2] Alvarez, Fernando, Patrick J. Kehoe, and Pablo Andre Neumeyer (2004) The time consistency of optimal monetary and fiscal policies. Econometrica 72, 541-67.

[3] Antinolfi, Gaetano, Costas Azariadis and James Bullard (2007) The optimal inflation target in an economy with limited enforcement. Federal Reserve Bank of St. Louis, Working Paper.

[4] Arseneau, David M. and Sanjay K. Chugh (2007) Optimal fiscal and monetary policy with costly wage bargaining. FRB International Finance Discussion Paper No. 893.

[5] Bhattacharya, Joydeep, Joseph Haslag, Antoine Martin and Rajesh Singh (2004) Who is afraid of the Friedman rule? manuscript. University of Missouri.

[6] Bhattacharya, Joydeep, Joseph Haslag and Antoine Martin (2005) Heterogeneity, redistribution, and the Friedman rule. International Economic Review 46 (2), 437454.

[7] Chari, V.V. and Patrick J. Kehoe (1998) Optimal fiscal and monetary Policy. Federal Reserve Bank of Minneapolis, Staff Reports.

[8] Cremer, Helmuth, Pierre Pestieau and Jean-Charles Rochet (2001) Direct versus indirect taxation: The design of the tax structure revisited. International Economic Review 42, 781-799. 
[9] da Costa, Carlos and Ivan Werning (2008) On the optimality of the Friedman rule with heterogeneous agents and non-linear income taxation. Journal of Political Economy 116, 82-112.

[10] De Nardi, Mariacristina, Selahattin İmrohorŏglu and Thomas Sargent (1999) Projected U.S. Demographics and Social Security. Review of Economic Dynamics 2(3), $575-615$.

[11] Ebert, Udo (1992) A reexamination of the optimal nonlinear income tax. Journal of Public Economics 49, 47-73.

[12] Garcia-Penalosa, Cecilia and Stephen Turnovsky (in press) Growth, income inequality, and fiscal policy: What are the televant tradeoffs? Journal of Money, Credit, and Banking.

[13] Heer, Burkhard (2003) Welfare costs of inflation in a dynamic economy with search unemployment. Journal of Economic Dynamics and Control 28, 255-272.

[14] Ireland, Peter (2005) Heterogeneity and redistribution: By monetary or fiscal means? International Economic Review 46, 455-463.

[15] Jin, Yi (in press) A note on inflation, growth, and income inequality. Macroeconomic Dynamics.

[16] Kocherlakota, Narayana (2005) Optimal monetary policy: What we know and what we don't know. International Economic Review 46, 715-729. 
[17] Ljungqvist, Lars and Thomas Sargent (2001) Recursive macroeconomic theory. MIT Press, Massachusetts.

[18] Mirrlees, James A. (1976) Optimal tax Theory: A synthesis. Journal of Public Economics $6,327-58$.

[19] Palivos, Theodore (2005) Optimal monetary policy with heterogeneous agents: a case for inflation. Oxford Economic Papers 57, 34-50.

[20] Schmitt-Grohe, Stephanie and Martin Uribe (2004) Optimal fiscal and monetary policy under imperfect competition. Journal of Macroeconomics 26, 183-209. 